\title{
Long-term therapy with cyclosporine and alternate-day prednisone in patients with idiopathic Steroid Resistant Nephrotic Syndrome (SRNS)
}

\author{
Devi $\mathbf{D}^{1}$, \\ ${ }^{1}$ Dr. Dipti Devi, Associate Professor of Pediatrics, KDMCH \& RC, Mathura, UP, India.
}

Corresponding Author: Dr. Dipti Devi : Ex IPNA Fellow in the Department of Pediatrics, All India Institute of Medical Sciences, New Delhi: Associate Professor of Pediatrics, KDMCH \& RC, Mathura, UP, India, E-mail: d_d1093@rediffmail.com

\begin{abstract}
Introduction: The treatment of SRNS, which comprises $10-20 \%$ patients with idiopathic nephrotic syndrome, is difficult. Currently calcineurin inhibitors are recommended as the $1^{\text {st }}$ line drug in idiopathic SRNS. Objective: Studies on cyclosporine are available for SRNS as early as 1980 . We report here our long-term experience with Cyclosporine \& prednisolone in these patients during those days of early experiences on cyclosporine. Methods: Case records of patients with idiopathic SRNS between 1995 \& 2006 were reviewed. Patients who received $>6$-months treatment with cyclosporine \& prednisolone were included. Those with onset in infancy \& Schwartz GFR $<60 \mathrm{ml} / \mathrm{min} / 1.73 \mathrm{~m}^{2}$ were excluded. Response was defined as complete remission, partial remission or non-response. Results: Of 58 patients, 32 had initial and 26 had late resistance. All received therapy with PO steroids. Some received PO/IV cyclophosphamide. The mean (SD) age at presentation \& treatment were 60.4 (38) \& 75 (43) months. All except one had pretreatment biopsy. Biopsy showed minimal change disease, focal segmented glomerulosclerosis and mesangioproliferative glomerulonephritis in 20,25 and 12 cases respectively. The mean time to onset of complete remission or partial remission was 3.3 (2.7) months \& duration of treatment was 22.4 (14.7) months. Complete remission, partial response, no response \& late cyclosporine resistance were seen in $48 \%, 33 \%, 12 \%$ \& $7 \%$ patients respectively. Responses were similar in patients with various histologic lesions. Of 18 patients re-biopsied after 2 years of therapy, 3 (16.7\%) showed evidence of cyclosporine toxicity, which were mild and manageable. Conclusion: Treatment with cyclosporine and alternate day prednisolone is effective and safe in patients with idiopathic SRNS.
\end{abstract}

Keywords: Idiopathic nephrotic syndrome, Steroid resistant, Cyclosporine therapy

\section{Introduction}

Idiopathic nephrotic syndrome is a clinical state characterized by heavy proteinuria, hypoalbuminemia and massive edema. It is the most common glomerular disease in children worldwide. It affects 2 per 1,00,000 children of 15 years or less per year [1,2]. The incidence is reported to be 4-6 times higher in Asian countries [3]. After an initial attack, spontaneous remission can occur in $5 \%$ of children with idiopathic nephrotic syndrome [4].

Others continue with a risk of all complications. As most of the children with idiopathic nephrotic syndrome is sensitive to steroid with a good prognosis [5], a standard dose of corticosteroid should be tried after controlling edema and infection. Routine pretreatment

Manuscript received: $20^{\text {th }}$ August 2018

Reviewed: $30^{\text {th }}$ August 2018

Author Corrected: $6^{\text {th }}$ September 2018

Accepted for Publication: $11^{\text {th }}$ September 2018 biopsy is not justified. The current therapeutic approach is based upon cohort studies initiated by the International Study of Kidney Diseases in Children between 1967 and 1974. The study used a regime of oral prednisolone $60 \mathrm{mg} / \mathrm{m} 2 /$ day maximum daily for 30 days followed by the same dose alternate day for total duration of 2.5 months for initial attack [6]. If the duration was shorter, remission was shorter with increased relapse rate [7,8]. APN compared 4 weeks daily and 4 weeks alternate day treatment with 6 weeks daily and 6 weeks alternate day regimen [9].

The relapse rate within 12 months were significantly lower in the $2^{\text {nd }}$ group ( $61 \%$ versus $\left.36 \%\right)$. A prospective randomized study on 73 children in Japan with $60 \mathrm{mg} / \mathrm{kg} /$ day for 4 weeks, $60 \mathrm{mg} / \mathrm{kg} /$ alternate day for next 4 weeks followed by tapering of $10 \mathrm{mg} / \mathrm{kg}$ every 2 weeks for total duration of 28 weeks alternate day 
resulted in increased remission rate significantly $(60 \%$ versus $0 \%$ ) at 2 years of follow up [10]. It assures that a more prolong course in initial attack may decrease relapse rate later. About $10-20 \%$ of children do not respond to 4-8 wks of daily prednisone [11]. Persistence defines steroid resistance. A histological diagnosis is mandatory in this setting as future course and prognosis is variable according to histology [12]. Steroid therapy should be withdrawn as prolonged high dose is toxic.

Again, with continued nephrosis, the short term or long term outcome is grim either due to complications of nephrotic syndrome like infections, malnutrition, thromboembolic events or progression to end stage renal disease. If nephrosis is continued after a period of follow up, 30-40\% of children develops ESRD [13,14]. Treatment of these children with continued nephrosis is difficult. Different modalities of treatment were being tried without any consensus. Recently calcineurin inhibitor is accepted as $1^{\text {st }}$ line treatment in these children [15]. Good results have been published with tacrolimus even in Cyclosporine resistant cases. Studies on cyclosporine for SRNS are available after its acceptance as an immunosuppressant in post transplant patients.

A retrospective study was done to evaluate our early experience with cyclosporine in 58 such children attending pediatric renal metabolic clinic of All India Institute of Medical Sciences, New Delhi. Though it looks like valueless now in presence of randomized control studies, it was an early step in the process of scientific pursuit. So, documentation of these pioneer works should be available in scientific journals as a motivation tool for research works to be continued.

\section{Materials and Methods}

The study was undertaken in the Pediatric Nephrology Division of Pediatric Department of All India Institute of Medical Sciences, New Delhi. It was a retrospective, observational, single center cohort study.

Inclusion criteria- The study population included 58 children attending the renal metabolic clinic between 1995 to 2006 and receiving cyclosporine and prednisolone for more than 6 months.

Exclusion criteria- Children with secondary nephrotic syndrome or onset less than one year of age or with decreased eGFR $<60 \mathrm{ml} / \mathrm{min} / 1.73 \mathrm{~m} 2$ were excluded.

Case Definition- Nephrotic syndrome was diagnosed based on criteria of nephrotic range of proteinuria $(\geq 2+$ urinary protein by dipstick or random $\mathrm{Ua} / \mathrm{Uc}>2$ ), hypoalbuminaemia (serum albumin $<2.5 \mathrm{gm} / \mathrm{dl}$ ) and edema. Initial steroid resistance was declared after no remission attained after 4 weeks of daily oral prednesolone $2 \mathrm{mg} / \mathrm{kg} /$ day in divided doses followed by $1.5 \mathrm{mg} / \mathrm{kg} /$ alternate day for another 4 weeks. Late steroid resistance was diagnosed in a case of relapse with no response after 4 weeks of daily prednesolone.

The response to treatment was classified as complete remission $(\mathrm{CR})$, partial remission (PR) or no response (NR). Complete remission was defined by absence of proteinuria, edema and serum albumin $>2.5 \mathrm{gm} / \mathrm{dl}$. Partial response was defined by proteinuria $1+$ or $2+$, $\mathrm{Ua} / \mathrm{Uc} 0.2-2$, serum albumin $>2.5 \mathrm{gm} / \mathrm{dl}$. Relapse was defined by reappearance of urine albumin $>2+$ for 3 consecutive days or presence of edema. Secondary cyclosporine resistance was defined as a relapsed case not responding to $2^{\text {nd }}$ course of cyclosporine.

Data Collection- All information were collected from the case files. All patients except one with single kidney were subjected to kidney biopsy before starting cyclosporine. Histological analysis was done by the same pathologist. All patients had baseline physical examination (with weight, height and blood pressure) and investigations (with urinalysis, serum albumin, cholesterol, creatinine and eGFR by Schwartz formula). Cyclosporine was started in two divided doses daily along with alternate day prednisolone. All received ACEI and supplemental calcium daily. All parents were instructed to examine morning urine albumin with dipstick. All patients had follow up at renal clinic monthly till remission and then 3 monthly for variable period.

No response was declared if there was continued nephrosis at 6months of therapy. In those with complete or partial response, the dose of cyclosporine was reduced to a maintenance dose and continued with tapered dose of prednisolone. Follow up visits included history, physical examination and investigations as baseline with attention for side effects of therapy or complications of nephrotic syndrome.

Drug level was not monitored routinely. Those who had drug level, it was maintained at $100-150 \mathrm{ng} / \mathrm{ml}$ at $10-12$ hours. If acute nephrotoxicity with increase of serum creatinine $>25 \%$ was noted, drug was reduced by $25 \%$. Likewise, at no response at 3 months, the drug dose was increased to $25 \%$.

If there was no response at 6 months cyclosporine was stopped and other form of therapy tried. Responding 


\section{Letter to Editor}

patients were followed up with continued therapy. Any relapse was treated with steroid first. Any patient with secondary resistance, different drugs were used. At the end of 2 years, repeat biopsy was done in 18 patients to rule out cyclosporine related toxicity.
Data Analysis- The data was entered into Microsoft excel 2000 and was analyzed by using SPSS version 7 crosstabs and frequencies were calculated. To compare two variables, chi- square test, one way ANOVA and P value with $<0.05$ for significance were applied .

\section{Results}

A total of 58 children received cyclosporine during the study period of 11 years for SRNS. There were 42 boys and 16 girls (M:F=72:28). There were 32 cases with initial resistance and 26 cases with late resistance $(55: 45)$

Table-1: Patient characteristic at the beginning of therapy.

\begin{tabular}{|c|c|}
\hline Mean age & $60.39 \pm 38.43 \mathrm{months}$ \\
\hline Mean weight & $17.28 \pm 7.8 \mathrm{~kg}$ \\
\hline Mean height & $100.19 \pm 18.9 \mathrm{~cm}$ \\
\hline Mean BMI & $17.35 \pm 2.62$ \\
\hline Mean systolic blood pressure & $109.87 \pm 15.7 \mathrm{~mm} \mathrm{of} \mathrm{Hg}$ \\
\hline Mean diastolic blood pressure & $76.03 \pm 12.6 \mathrm{~mm}$ of Hg \\
\hline Mean proteinuria & $3.32 \pm 0.6+$ by dipstick \\
\hline Mean serum albumin & $1.98 \pm 0.84 \mathrm{gm} / \mathrm{dl}$ \\
\hline Mean serum cholesterol & $410.7 \pm 184.12 \mathrm{mgm} / \mathrm{dl}$ \\
\hline Mean serum creatinine & $0.656 \pm 0.26 \mathrm{mgm} / \mathrm{dl}$ \\
\hline Mean estimated GFR & $92 \pm 26.8 \mathrm{ml} / \mathrm{min} / 1.73 \mathrm{~m} 2$ \\
\hline
\end{tabular}

At the beginning, there was continued nephrosis with normal renal function.

Table-2: Biopsy diagnosis at the beginning of therapy.

\begin{tabular}{|c|c|c|c|}
\hline MCD & Male 17(85\%) & Female 3(15\%) & Total 20(34\%) \\
\hline MesPGN & $5(42 \%)$ & $7(58 \%)$ & $12(21 \%)$ \\
\hline FSGS & $19(76 \%)$ & $6(24 \%)$ & $25(43 \%)$ \\
\hline Not done & $1(100 \%)$ & 0 & $1(2 \%)$ \\
\hline
\end{tabular}

Pre-treament biopsy diagnosis showed all 3 histological types.

Table-3: Biopsy diagnosis related to age

\begin{tabular}{|c|c|c|c|}
\hline Biopsy & Age at onset of NS & Age at the presentation of SRNS & Age at start of cyclosporine \\
\hline MCD & $40.42 \mathrm{~m} \pm 18 \mathrm{~m}$ & $56 \mathrm{~m} \pm 20 \mathrm{~m}$ & $64 \mathrm{~m} \pm 13 \mathrm{~m}$ \\
\hline MesPGN & $28.08 \pm 16.2 \mathrm{~m}$ & $40.9 \pm 20.4 \mathrm{~m}$ & $67.9 \pm 37.7 \mathrm{~m}$ \\
\hline FSGS & $50.48 \pm 43.5 \mathrm{~m}$ & $75.28 \pm 44.8 \mathrm{~m}$ & $88.4 \pm 49.2 \mathrm{~m}$ \\
\hline P value & 0.24 & 0.06 & 0.17 \\
\hline
\end{tabular}

Mean age for FSGS was higher than other histological types at all course of the disease prior to cyclosporine, but the difference was statistically insignificant.

Table-4: Cyclosporine therapy.

\begin{tabular}{|c|c|}
\hline Mean age at starting & $74.68 \pm 43.4 \mathrm{~m}$ \\
\hline Mean dose at starting & $4.8 \pm 0.66 \mathrm{mg} / \mathrm{kg}$ \\
\hline Mean time for response & $3.34 \pm 2.7 \mathrm{~m}$ \\
\hline Mean duration & $22.4 \pm 14.67 \mathrm{~m}$ \\
\hline
\end{tabular}

Cyclosporine was started at $4.8 \pm 0.66 \mathrm{mg} / \mathrm{kg} / \mathrm{d}$ for mean period of 2 yrs. The meantime to respond was 3.34 months. 
Table-5: Prednisone Therapy.

\begin{tabular}{|l|c|l|}
\hline Mean dose at start & $1.24 \pm 0.5 \mathrm{mg} / \mathrm{kg}$ & \\
\hline Mean dose at $6 \mathrm{~m}$ & $0.715 \pm 0.35 \mathrm{mg} / \mathrm{kg}$ & \\
\hline Mean dose at $12 \mathrm{~m}$ & $0.5 \pm 0.32 \mathrm{mg} / \mathrm{kg}$ & \\
\hline Mean dose at $24 \mathrm{~m}$ & $0.46 \pm 4 \mathrm{mg} / \mathrm{kg}$ & \\
\hline Mean dose at $48 \mathrm{~m}$ & $0.42 \pm 0.31 \mathrm{mg} / \mathrm{kg}$ & \\
\hline
\end{tabular}

Prednesolone was added to cyclosporine at a mean dose of $1.24 \mathrm{mg} / \mathrm{kg}$ on alternate day and after 6 months gradually tapered.

Table-6: Options before cyclosporine.

\begin{tabular}{|c|c|}
\hline Oral Prednisolone & $11(18.9 \%)$ \\
\hline Oral pred + oral cyclophosphamide & $4(6.8 \%)$ \\
\hline Oral pred + IV cyclophosphamide & $14(24 \%)$ \\
\hline Pulse methyl pred + oral pred & $3(5 \%)$ \\
\hline Pulse methyl pred + IV cyclo+ oral pred & $7(12 \%)$ \\
\hline Oral pred+ oral cyclophos+ IV cyclophos & $4(6.8 \%)$ \\
\hline Oral pred+ Pulse methyl + oral cyclophos & $8(13.6 \%)$ \\
\hline Oral pred+oral cyclophos +IV cyclophos & $6(10 \%)$ \\
\hline Oral pred+ pulse methyl+ IV cyclopho+MMF & $1(1.8 \%)$ \\
\hline
\end{tabular}

Drugs like oral prednisolone, pulse methyl prednisolone, oral or IV cyclophosphamide, MMF were tried in these children before cyclosporine in various combinations.

Table-7: Response according to tissue diagnosis

\begin{tabular}{|c|c|c|c|c|}
\hline Response & MCD & MesPGN & FSGS & Total \\
\hline No response & $2(10 \%)$ & $1(8.3 \%)$ & $4(16 \%)$ & $7(12.3 \%)$ \\
\hline Partial response & $2(10 \%)$ & $5(41.7 \%)$ & $12(48 \%)$ & $19(33.3 \%)$ \\
\hline Complete response & $15(75 \%)$ & $3(25 \%)$ & $9(36 \%)$ & $27(47.4 \%)$ \\
\hline Secondary resistance & $1(5 \%)$ & $3(25 \%)$ & 0 & $4(7 \%)$ \\
\hline
\end{tabular}

Response was as highest in MCD (85\%), followed by FSGS (84\%). Overall response was seen in $80.7 \%$ of cases. When the response to cyclosporine was analyzed against sex, the age of onset, duration of the disease, duration between starting the alternative therapy and cyclosporine, the results were not statistically significant.

Table- 8: Side effects

\begin{tabular}{|c|c|}
\hline Side effects & \\
\hline Hypertrichosis & $8(13.7 \%)$ \\
\hline Gum hyperplasis & $6(10.8 \%)$ \\
\hline Hypertension & $6(10.8 \%)$ \\
\hline Relapse & $14(24 \%)$ \\
\hline Acute nephrotoxicity & $6(10.8 \%)$ \\
\hline Infection & $4(6.8 \%)$ \\
\hline Histological cyclosporine toxicity & $3(9 \%)$ \\
\hline
\end{tabular}

Side effects were mild and manageable. 


\section{Discussion}

The clinical, histological and recently genetic mutational characteristics of SRNS have been published in different studies. Early reports estimated that $10 \%$ of idiopathic nephrotic children do not respond to corticosteroid [11]. A recent study found $27 \%$ of children not responding [16].

There is considerable variation in case definition in different studies. The ISKDC defined $<4 \mathrm{mg} / \mathrm{m} 2 / \mathrm{hr}$ as criteria for remission [17]. Some studies used ISKDC definition of $<4 \mathrm{mg} / \mathrm{m} 2 / \mathrm{hr}$ as criteria for complete remission and ignored partial remission. Patients with PR are more likely to respond to cyclophosphamide or cyclosporine and do not progress to ESRD [18,19]. Some studies used 3 pulses of Methyle prednisolone for definition of steroid resistance after 1 month of daily prednisolone [20].

ISKDC showed that $80 \%$ of children of idiopathic nephrotic syndrome are $<6$ yrs at presentation, mean age of $2.5 \mathrm{yrs}$ for MCD and $6.8 \mathrm{yrs}$ for FSGS [17]. The ISKDC lacked information on patient ethnicity. Later it was reported that the incidence of SRNS is higher in African American and older children [11].

The risk for primary steroid resistance depends on initial histopathology. Studies by ISKDC showed that $70 \%, 44 \%$ and $7 \%$ of FSGS, Mes PGN and MCD respectively behave like initial resistance [17]. Several studies are reporting that though the incidence of INS is same, the FSGS is increasing [21]. In a cohort of 115 African American children 16\% of SSNS developed late resistance. Of them, $42 \%, 47 \%$ and $1 \%$ were FSGS, MCD and MesPGN respectively [11]. Among children with MCD, 3\% become steroid resistant later. Early relapse and first relapse were reported as predisposing factor for late resistance [5]. Children with MCD or late steroid resistance generally respond better to immunosuppressive therapy than children with FSGS or initial steroid resistance [12,22-24].

Few studies on European, American and Turkish children found that $30 \%$ of sporadic SRNS had mutation in NPHS2 encoding podocin [25-27]. However, all children of $1^{\text {st }}$ attack do not need screening as only $10-20 \%$ are SRNS and out of it approximately $20 \%$ have mutation. This is not applicable to a $1^{\text {st }}$ episode of NS with family history of steroid resistance [28]. Mutation causing recessive SRNS in children were found in other genes also like NPHS1, LAMB2, PLCE1 and CD2AP [29]. The rate of disease-causing mutation was similar in Caucasian and
Asian or South korea and Italy [30]. No children with NPHS2 mutation responded to complete remission with alkylating agent or cyclosporine. Few have partial response. Recurrence is rare. In contrast $30 \%$ of children without mutation have recurrence [25]. Children with late resistance do not have mutation [22]. A recent report published absence of NPHS2 mutations in African American SRNS children [30].

An immune mediated permeability factor has a key role in leaking of protein in children with idiopathic nephrotic syndrome without genetic mutation. Following a standard course of steroid either initial or late resistance pattern may emerge in a small and yet challenging group of children. Different modalities of immunosuppression are being tried so far. Prolonged corticosteroid for 6-12 months may have a remission rate of $28 \%$ with increased rate of iatrogenic complications [5]. A partial or complete remission was reported with oral cyclospsphamide with a remission rate close to continued steroid therapy alone [31]. One trial compared oral cyclophosphamide with IV cyclophosphamide and reported no significant difference [32].

A more aggressive treatment with vincristine, cyclophosphamide and prednisone was not helpful [33]. Another aggressive approach with pulse methyl prednisolone for 6 months, oral alternate day prednisolone and oral cyclospshosphamide or chlorambucil for 8-12 weeks reported after 6 years of follow up that 21 of 32 children in complete remission and end stage renal disease in 5\% only versus $40 \%$ of controls [34]. Children with FSGS showed poor outcome. Mendouza reported remission rate of $44-82 \%$ [14]. Mori added cyclophosphamide to consolidate [35]. MCD responded better in some studies. The response rate was higher in some studies in LR, while similar with IR in some other studies. 7\% developed ESRD. There was no side effect of alkylating agents. Pulse methyl prednisolone with or without alkylating agents showed failure rate $18-25 \%$ in $78-100 \%$ cases vs $100 \%$ in $20 \%$ cases. Later a multicenter study without alkylating agent could not confirm efficacy of pulse methyl prednesolone [36]. Two RCT demonstrated significant reduction of proteinuria with ACEI [37,38]. No study shows benefit of azathioprine [39].

Cyclosporine was the most commonly used drug in SRNS. Cyclosporine is a cyclic peptide extracted from fungus Tolipocladium inflatum. It acts on T helper cells by inhibiting IL2 production. It combines with 
cyclophillin and suppresses mRNA transcription and cell proliferation $[40,41]$. It reduces proteinuria by two mechanisms: one by immunosuppression and second by increase in cyclic AMP. Several studies since 1980 show its effects in SRNS. Initial eight uncontrolled studies with cyclosporine revealed 20\% complete remission. Maher et al studied 11 patients of frequent relapse SSNS (10 MCNS,1 IgM nephropathy) and 4 patients of SRNS (FSGS) with $7.7 \mathrm{mg} / \mathrm{kg} /$ day cyclosporine $\mathrm{He}$ reported complete remission in all MCNS within a mean of 14.3 days followed by maintenance.

There were no adverse effects. However, the other patients with FSGS and IgM nephropathy did not respond [42]. When oral prednisolone was added the remission rate was higher [43-46]. The French Society of Pediatric Nephrology reported that 150$200 \mathrm{mg} / \mathrm{kg} /$ day of oral cyclosporine with $30 \mathrm{mg} / \mathrm{kg} /$ day prednisolone for 1 months, then alternate day resulted in $42 \%$ complete remission in 6 months. Of total 65 cases, $48 \%$ and $30 \%$ were MCD and FGS respectively. Further relapse of 8 of 27 cases were prednisolone sensitive, while 17 cases were free of proteinuria at the end of 3 years of follow up. None progressed to ESRD. Most of the non-responder were FSGS [23]. Another study enrolling 15 children with $6.3 \mathrm{mg} / \mathrm{kg} /$ day of cyclosporine with trough level of $70-120 \mathrm{ng} / \mathrm{ml}$ went in remission at 2 months in $87 \%$ [47]. Efficacy of cyclosporine was proved in several trials. The systematic review updated in 2006 analyzed 11 RCT involving 280 children [39]. FSGS acquired CR in 36\%.

Also there was PR. According to Ponticelli, the dose should be tapered after 1 year and stopped at $6 \mathrm{~m}$. In case of relapse, he restarted another course [6]. In a retrospective case series, out of 51 children without mutation $77 \%$ achieved remission by cyclosporine and prednisolone with or without pulse methylprednisolone [12]. One randomized controlled trial with 22 patients, 7 and 6 patients had CR and PR at 6 month. No control had CR, only 3 out of 9 had PR [48].

Another study reported ESRD at the end of 5 years in $24 \%$ with cyclosporine versus $78 \%$ control of FGS [49]. A multicenter RCT by APN compared cyclosporine with IV cyclophosphamide and reported that cyclosporine is more effective [50]. RCTs have shown that cyclosporine has a significant increase in remission rate than the placebo [51] or supportive therapy [52].

While treating patients, side effects are reported in various studies as nephrotoxicity (6-41\%), high blood pressure (10-36\%), hirsuitism (13-70\%), gingival hypertrophy (22-32\%), cyclosporine dependence (50$85 \%$ ), cyclosporine resistance (25-50\%) and ESRD (20$50 \%$ [53]. Most are manageable. In SRNS with normal renal function and without severe hypertention, cyclosporine does not produce severe renal and extrarenal toxicity. Cyclosporine related nephrotoxicity is a major concern as it is nonreversible. Cattan et al reported 50\% reduction in renal function [53]. A level of $100 \mathrm{ng} / \mathrm{ml}$ was maintained in some studies to balance efficacy and toxicity. Adhikari et al reported trough level between $180-875 \mathrm{ng} / \mathrm{ml}$ and peak levels between 563 and $1950 \mathrm{ng} / \mathrm{ml}$ at 24 months. 3 of 5 patients had no cyclosporine related toxicity, while 2 developed toxicity.

He concluded that Cyclosporine should be given at lower doses and level monitored frequently [54]. A young age with higher frequency of relapses, duration of cyclosporine and duration of proteinuria predispose to nephrotoxicity. A single daily dose with higher peak level at 2 hours may have few relapses and so reduced toxicity and improved compliance. Tubular atrophy with striped interstitial fibrosis is the most reliable indicator of cyclosporine related toxicity. Severity is graded as grade1 (normal histology), 2(mild, interstitial fibrosis $<50 \%$ ), 3(moderate to severe, Interstitial fibrosis $>.50 \%$ ) [52].

SRNS is the commonest cause of glomerular disease causing ESRD [46]. Different modalities of treatment are being tried. Recent knowledge of genetic mutation in SRNS is continuously growing. Most studies have not excluded genetic mutation before treatment. Inclusion may lead to altered interpretation of result. Till now, no SRNS with mutation is reported to have CR after immune-suppression. There may be partial remission. However, even achieving a partial remission is acceptable. As it may be protective in otherwise relentless progression to ESR specially in a FSGS. Such a case may have steroid sensitive relapse later. Children with MCD or late resistance generally do better to immune-suppression Different modalities of immunesuppression were used in different centers with considerable variability from definitions of steroid resistance itself.

Some studies used ISKDC definitions. Some others did not mention complete or partial remission. There was no standardization of therapy with dose and duration of various drugs also in various studies. Cyclosporine was the most used drug in different studies. However variable rate of remission from $24-100 \%$ were achieved. It was recommended as first line of therapy in SRNS children [39]. An optimal treatment protocol with low 
Letter to Editor

to moderate dose is desirable. We also experienced a high remission rate. The mean time to onset of complete remission or partial remission was 3.3 (2.7) months \& mean duration of treatment was 22.4 (14.7) months. Complete remission, partial response, no response \& late cyclosporine resistance were seen in $48 \%, 33 \%$, $12 \% \& 7 \%$ patients respectively. Responses were similar in patients with various histologic lesions.

We had a prolonged follow up of 60 months. The side effects were found mild and manageable. Relapses at follow up resolved after treatment of infection or increasing the dose of cyclosporine or prednisolone except one case with secondary resistance to cyclosporine. Of 18 patients re-biopsied after $2 \mathrm{yr}$ of therapy, $3(16.7 \%)$ showed evidence of cyclosporine toxicity, which were mild and manageable.

Though our study had limitations of a retrospective case cohort, a good number of children were followed up for a prolonged period in a single centre with same working group. There is uniformity of clinical and pathological presentation and treatment protocol. There was a high remission rate. There was no typical cyclosporine related toxicity in rebiopsy. In recent years many studies came up confirming our observations. Li J et al concluded that CsA and Tac as initial therapy for SRNS have a better remission and relapse rate[55]. Genetic screening should be done prior to therapy in familial SRNS and ideally in sporadic SRNS also with initial resistance. Till it is available universally, achievement of PR by immune-suppression may be protective against ESRD in a good number of sporadic SRNS.

\section{Conclusion}

Our study revealed that cyclosporine is a good and safe therapeutic option for SRNS.

Funding: Nil, Conflict of interest: None initiated, Perission from IRB: Yes

\section{References}

1. McKinney PA, Feltbower RG, Brocklebank JT, Fitzpatrick MM. Time trends and ethnic patterns of childhood nephrotic syndrome in Yorkshire, UK. PediatrNephrol. 2001 Dec;16(12):1040-4. DOI:10. 1007 / s004670100021

2. Wong W. Idiopathic nephrotic syndrome in New Zealand children, demographic clinical features, initial management and outcome after twelve months follow up: results of a three year national surveillance study. J Paediatric Child Health 2007;43:337-341
3. Sharples PM, Poulton J, White RH. Steroid responsive nephrotic syndrome is more common in Asians. Arch Dis Child. 1985 Nov; 60 (11):1014-7.

4. P Niaudet. Treatment of idiopathic nephritic syndrome in children Up To Date www.uptodate.com

5. Tarshish P, Tobin JN, Bernstein J, Edelmann CM J. Prognostic significance of the early course of minimal change nephritic syndrome : report of the International Study of Kidney Disease in Children. J Am Soc Nephrol 1997;8:769-776

6. Ponticelli C, Rizzoni G, Edefonti A, et al. A randomized trial of cyclosporine in steroid-resistant idiopathic nephrotic syndrome. Kidney Int. 1993 Jun; 43 (6):1377-84.

7. Arbeitsgemeinschaft fur Padiatrische Nephrology. Short versus standard prednisone therapy for initial treatment of idiopathic nephrotic syndrome in children. Lancet 1988;1;380

8. Hodsone E, Knight J, Willis N, Craig J. Corticosteroid therapy for nephritic syndrome in children Cochrane database syst rev 2004; 2: CD00 1533

9. Brodehl J. The treatment of minimal change nephrotic syndrome: lessons learned from multicentre co-operative studies. Eur J Pediatr. 1991 Apr;150 (6): 380-7.

10. Hiraoka M, Tsukahara $H$, Matsubara $K$, et al. A randomized study of two long-course prednisolone regimens for nephrotic syndrome in children. Am J Kidney Dis. 2003 Jun;41(6):1155-62.

11. Kim JS, Bellew CA, Silverstein DM, et al. High incidence of initial and late steroid resistance in childhood nephrotic syndrome. Kidney Int. 2005 Sep;68(3): 1275-81. DOI: 10.1111/j. 1523-1755. 2005. 00524.x

12. Ehrich JH, Geerlings C, Zivicnjak M, et al. Steroidresistant idiopathic childhood nephrosis: over diagnosed and undertreated. Nephrol Dial Transplant. 2007 Aug; 22 (8): 2183-93. Epub 2007 May 15. DOI:10.1093/ ndt/gfm092

13. Cattran DC, Rao P. Long-term outcome in children and adults with classic focal segmental glomerulosclerosis. Am J Kidney Dis. 1998 Jul; 32 (1): 72-9. 
Letter to Editor

14. Mendoza SA, Reznik VM, Griswold WR, et al. Treatment of steroid-resistant focal segmental glomerulosclerosis with pulse methylprednisolone and alkylating agents. Pediatr Nephrol. 1990 Jul; 4 (4): 303-7.

15. Tsugawa K, Tanaka H, Nakahata T, Ito E (2004) Effective therapy of a child case of refractory nephrotic syndrome with tacrolimus. Tohoku J Exp Med 204: 237-241.

16. Nammalwar BR, Vijaykumar M, Prahlad N, Jain DV. Steroid resistant nephrotic syndrome is sustained remission attainable. Indian Pediatr. 2006 Jan; 43 (1): $39-43$.

17. International Study in Kidney Disease in Children. The primary nephrotic syndrome in children. Identification of patients with minimal change nephrotic syndrome from initial response to prednisolone. A report of ISKDC. J Pediatr 1981;98:561-564

18. Abrantes MM, Cardosa LSB, Lima EM, Silva JMP, Diniz JS, Bambirra EA, Oliveira EA. Clinical course of 110 children and adolescents with primary focal segmental glomerulosclerosis. Pediatr Nephrol 2006; 21:482-489

19. Pankaj Hari. R.N. Srivastava Pulse corticosteroid therapy with methylprednisolone or dexamethasone Indan J Pediatr 1998;65: 557-560

20. Murnaghan K, Vasmant D, Bensman A. Pulse methylprednisolone in severe idiopathic childhood nephritic syndrome Acta Pediatric Scand 1984; 73: 733

21. Borges FF, Shiraichi L, da Silva MP, et al. Is focal segmental glomerulosclerosis increasing in patients with nephrotic syndrome? Pediatr Nephrol. 2007 Sep;22(9):1309-13. Epub 2007 Jun 6. DOI:10.1007/ s00467-007-0516-0

22. Schwaderer P, Knuppel T, Konrad M, Mehls O, Scharer K, Schaefer F, Weber S. Clinical course and NPHS2 analysis in patients with late steroid resistant nephotic syndrome Pediatr Nephrol 2008; 23: 251256

23. Niaudet P. Treatment of childhood steroid resistant idiopathic nephrosis with a combination of cyclosporine and prednisone. French Society of Pediatric Nephrology. J Pediatr 1994;125: 981-986
24. Pena A, Bravo J, Melgosa M. Fernandez C, Merceguer C, Espinosa L, Alonso A, Picazo ML, Navarro M. Steroid resistant nephritic syndrome: long term evaluation after sequential therapy. Pediatr Nephrol 2007;22: 1875-1880

25. Ruf RG, Lichtenberger A, Karle SM, Hass JP, Anaclato FE, Schultheiss M, Zalewiski, I, Imm A, Ruf EM, Mucha B, Bagga A, Neuhas T, Fuchshuber A, BakkalogluA, Hildebrandt F. Patients with mutations in NPSH2 (podocin) do not respond to standard steroid treatment of nephritic syndrome. J Am Soc Nephrol 2004; $15:: 722-732$

26. Weber S, Gribouval O, Esquivel EL, et al. NPHS2 mutation analysis shows genetic heterogeneity of steroid-resistant nephrotic syndrome and low posttransplant recurrence. Kidney Int. 2004 Aug;66(2):5719. DOI:10.1111/j.1523-1755.2004.00776.x

27. Berdeli A, Mir S, Yavascan O, Serdaroglu E, Bak M, Aksu N, Oner A, Anarat A, Donmez O, Yildiz N, Sever 1, Table Y, Dusunselr, Sonmez F, Cakar N. NPHS2 (podocin)mutations in Tarkish children with idiopathic nephritic syndrome. Pediatr Nephrol 2007; 22: 2031-2040

28. Niaudet P. Podocin and nephrotic syndrome: implications for the clinician. J Am Soc Nephrol. 2004 Mar; 15(3):832-4.

29. Ruf RG, Schultheiss M, Lichtenberger A, et al. Prevalence of WT1 mutations in a large cohort of patients with steroid-resistant and steroid-sensitive nephrotic syndrome. Kidney Int. 2004 Aug;66(2):56470. DOI:10.1111/j.1523-1755.2004.00775.x

30. Gil Chernin.Saskia F. Heeringa.Rashid Gbadegesin. Jinhong Liu. Bernward G. Hinkes. Chritopher N. Vlangos. Virginia Vega - Warner. Friedhelm Hildebrandt Low prevalence of NPHS2 mutations in African American children with steroid- resistant nephritic syndrome Pediatr Nephrol(2008)23:14551460

31. Martinelli R, Pereira LJ, Silva OM, et al. Cyclophosphamide in the treatment of focal segmental glomerulosclerosis. Braz J Med Biol Res. 2004 Sep; 37 (9): 1365-72. Epub 2004 Aug 24. DOI:/S0100879X2004000900010

32. Elhence R, Gulati S, Kher V, et al. Intravenous pulse cyclophosphamide--a new regime for steroidresistant minimal change nephrotic syndrome. Pediatr Nephrol. 1994 Feb;8(1):1-3. 
Letter to Editor

33. Trompeter Rs SRNS, a review of of the treatment of FSGS in children In: recent advances in ped nephrology, Murakami K, Kitagawa T, Yabuta K, Sakai T(Eds) Experta Medica , Amsterdam, 1987,pp 363-371

34. Tune BM, Kirpekar R, Sibley RK, et al. Intravenous methylprednisolone and oral alkylating agent therapy of prednisone-resistant pediatric focal segmental glomerulosclerosis: a long-term follow-up. Clin Nephrol. 1995 Feb;43(2):84-8.

35. Guillot AP, Kim MS Pulse steroid therapy does not alter the course of focal segmental glomerulosclerosis $\mathbf{J}$ Am Soc Nephrol 1993; 4:276]

36. Bagga A, Mudigoudar BD, Hari P, Vasudev V. Enalapril dosage in steroid-resistant nephrotic syndrome. Pediatr Nephrol. 2004 Jan;19(1):45-50. Epub 2003 Nov 25. DOI:10.1007/s00467-003-1314-y

37. Yi Z, Li Z, Wu XC, HeQN, Dang XQ, He XJ. Effect of fosinopril in children with steroid resistant idiopathic nephrotic syndrome Pediatr Nephrol 2006; 21: $967-972$

38. Hodson EM, Habashy D,Craig JC Interventions for idiopathic steroid resistant nephritic syndrome in children (Cochrane review) From the Cochrane Library, Issue 3, 2006.

39. Zietse R, Derkx FH, Schalekamp MA, Weimar W. Cyclosporin and the glomerular filtration barrier in minimal change disease and membranous glomerulopathy. Contrib Nephrol. 1995;114:6-18.

40. Borel JF, Feurer C, Gubler HU, Stähelin H. Biological effects of cyclosporin A: a new antilymphocytic agent. 1976. Agents Actions. 1994 Dec; 43 (3-4):179-86.

41. E. R. Maher, P. Sweny, M. Chappel, Z. Varghese and J.F. Moorhead Cyclosporin in the treatment of steroid responsive and steroid resistant Nephrotic syndrome in adults Nephrol Dial Transplant 1988; 3: 728-732

42. Hymes LC. Steroid-resistant, cyclosporineresponsive, relapsing nephrotic syndrome. Pediatr Nephrol. 1995 Apr;9(2):137-9.

43. Hafeez F, Ahmad TM, Anwar S. Efficacy of steroids, cyclosporin and cyclophos-phamide in steroid resistant idiopathic nephrotic syndrome. J Coll
Physicians Surg Pak. 2005 Jun; 15 (6): 329-32. DOI:06.2005/JCPSP.329332

44. Tejani A Suthanthiran M, Pomrantz A. A randomized controlled trial of low dose prednisone and ciclosporin versus high dose prednesone in nephritic syndrome of children. Nephron 1991;59:96-99

45. Niaudet P.Treatment of childhood steroid resistant idiopathic nephrosis with a combination of cyclosporine and prednisone. French Society of Pediatric Nephrology. J Pediatr 1994;125: 981-986

46. Gregory MJ, Smoyer WE, Sedmanet Long term cyclosporine therapy for pediatric nephritic syndrome.: A clinical and histologic analysis. J Am Soc Nephrol 1996; 7:543,

47. Ponticelli C, Edefonti A, Ghio L, et al. Cyclosporin versus cyclophosphamide for patients with steroiddependent and frequently relapsing idiopathic nephrotic syndrome: a multicentre randomized controlled trial. Nephrol Dial Transplant. 1993;8(12):1326-32.

48. Ingulli E, Singh A, Baqi N, et al. Aggressive, longterm cyclosporine therapy for steroid-resistant focal segmental glomerulosclerosis. J Am Soc Nephrol. 1995 Apr;5(10):1820-5.

49. Plank C, Kalb V, Hinkes B, Hildebrandt F, Gefeller $\mathrm{O}$, Rascher W; Arbeitsgemschaft fur Padiatrische Nephrology. Cyclosporine A is superior to cyclophosphamide in children with steroid resistant nephrotic syndrome- a randomized controlled multicenter trial by the Arbeitsgemschaft fur Padiatrische Nephrology. Pediatr Nephrol 2008; DOI 10.1007/s00467-008-0794-1

50. Ponticelli C, Rizzoni G, Edefonti A, et al. A randomized trial of cyclosporine in steroid-resistant idiopathic nephrotic syndrome. Kidney Int. 1993 Jun;43 (6): 1377-84.

51. Lieberman KV, Tezani A. A randomized double blind placebo controlled trial on cyclosporine in SR FSGS in children J Am Soc Nephrol 1996;7; 56-63

52. Valerie Leroy. Veronique Baudouin. Corinne Alberti. Genevieve Guest.Patrick Niaudet. Chantal Loirat. Georges Deschenes. Paul Czernichow. Dominique Simon Growth in boys with idiopathic nephritic syndrome on long- term cyclosporine and steroid treatment Pediatr Nephrol(2009) 24:2393-2400 


\section{Letter to Editor}

53. Cattran DC, Rao P. Long term outcome in children and adults with classic focal segmental glomerulosclerosis.Am J Kidney Disease 1988;32:72-79

54. Adhikari M, Coovadia HM Cyclosporin in SRNS S Afr Med J 1994 Nov;(11);783-6
55. J Li, Q Li, J Lu and $\mathrm{Z} \mathrm{Li}$ : Immunosuppression therapy in children with steroid resistant nephrotic syndrome. Iran J Pediatr. 2018; 28 (1): e11567. Doi 10, 5812/ijp. 11567

\section{How to cite this article?}

Devi D. Long-term therapy with cyclosporine and alternate-day prednisone in patients with idiopathic Steroid Resistant Nephrotic Syndrome (SRNS). Int J Pediatr Res. 2018;5(11):582-591.doi:10.17511/ijpr.2018.i11.06. 